\title{
Production of Terephthalic Acid from Corn Stover Lignin
}

\author{
Song Song ${ }^{+}$, Jiaguang Zhang+, Gökalp Gözaydın and Ning Yan*
}

\begin{abstract}
Funneling and functionalization of a mixture of ligninderived monomers into a single high-value chemical is fascinating. Herein, we report a three-step strategy for the production of terephthalic acid (TPA) from lignin-derived monomer mixtures, in which redundant, non-uniform substitutes such as methoxyl groups are removed and the desired carboxyl groups are introduced. This strategy begins with the hydro-treating of corn stover-derived lignin oil over supported molybdenum catalyst to selectively remove methoxyl groups. The generated 4-alkylphenols are converted into 4-alkylbenzoic acids via carbonylation with carbon monoxide. The $\mathrm{Co}-\mathrm{Mn}-\mathrm{Br}$ catalyst then oxidizes various alkyl chains into carboxyl groups, transforming the 4-alkylbenzoic acids mixture into a single product: TPA. Based on this route, the overall yields of TPA based on lignin content of corn stover could reach $15.5 \mathrm{wt} \%$, and importantly, TPA with $>99 \%$ purity was obtained simply by first decanting the reaction mixture, followed by washing the solid product with water
\end{abstract}

Lignocellulose as an abundant and renewable source for various chemicals has attracted substantial attention over the last decade. ${ }^{[1]}$ Terephthalic acid (TPA), consumed primarily in polyethylene terephthalate manufacturing for making clothing and plastic bottles, is a critical commodity chemical with an expected market value of 110.66 billion USD by 2025. [2] In industry, TPA is produced by the oxidation of $p$-xylene, which is derived from catalytic reforming of petroleum feedstock. ${ }^{[3]}$ Production of TPA from renewable biomass feedstock has been attracting much research interest. ${ }^{[4]}$ In recent years, the ongoing shift from naphtha to lighter feed slates (ethane in particular) in the crackers considerably compromise the production of heavier products such as $p$-xylene, ${ }^{[5]}$ making the development of alternative ways to prepare TPA a more pressing issue.

Previous studies mainly focus on the utilization of cellulose or hemicellulose-based platform molecules as substrates to produce $p$-xylene and/or TPA. ${ }^{[4]}$ As the most abundant aromatic biopolymer on earth, lignin has been proven as a suitable renewable resource to produce certain aromatic chemicals, ${ }^{[16,1 d}$ ${ }^{1 e]}$ such as phenol[6]. Recently, a report claims to convert vanillic acid and syringic acid to TPA with an overall yield of $39 \% .{ }^{[7]}$ Although these two acids are in principle available via lignin oxidation, their combined yields are typically below $5 \mathrm{wt} \%{ }^{[8]}$ making the route impractical. Compared to the oxidation treatment of lignin, reductive lignin depolymerization affords a much higher yields of aromatic monomers. ${ }^{[1 \mathrm{c},}$ 1e] Starting from

[*] Dr. S. Song, Dr. J. Zhang, Mr. G. Gözaydın, Prof. Dr. N. Yan Department of Chemical \& Biomolecular Engineering

National University of Singapore

4 Engineering Drive 4, Singapore 117585

E-mail: ning.yan@nus.edu.sg

$\left.{ }^{+}\right]$These authors contributed equally to this work.

Supporting information for this article is given via a link at the end of the document. birch wood, for instance, the total monomer yields reached up to $46 \%$, with guaiacyl- and syringyl- type compounds as the main components. ${ }^{[9]}$ Even higher yields $(78 \%)$ of monomers comprising mainly guaiacyl and syringyl monomers with 4propyl- and 4-ethyl- substitutions have been more recently achieved from poplar wood lignin with the addition of formaldehyde as a stabilizer. ${ }^{[10]}$ From an engineering perspective, the flowthrough reductive catalytic fractionation technology, which enables the continuous production of lignin monomers, has also become viable. ${ }^{[11]}$

Despite these advances, efficient transformation of the monomeric mixtures derived from reductive depolymerisation of lignin into an easily purifiable, single-component, value-added chemical remains a challenge. Inspired by the recent exciting achievement to convert complex lignin degradation products via a biological funneling strategy, ${ }^{[12]}$ herein, we communicate a route for the chemical transformation of corn stover-derived lignin oil mixtures into TPA (Scheme 1). In the first step, the methoxyl groups in the lignin-derived phenolics are removed by de-methoxylation, simplifying the stream into a mixture of 4alkylphenols (step 1). These substituted phenols are further converted into a mixture of 4-alkylbenzoic acids by carbonylation to introduce the first - $\mathrm{COOH}$ group (step 2). Oxidation of the alkyl groups affords the second - $\mathrm{COOH}$ group, further narrowing down the stream to a single product TPA (step 3). Corn stover was used as the raw lignocellulose to demonstrate the feasibility of this strategy. For each step, simple model substrates were used first to identify effective catalysts and suitable reaction conditions, and then real lignin oil from corn stover (for step 1), or a mixture of substrates obtained from the previous step (for steps 2-3) was tested to ensure the feasibility of the entire route.

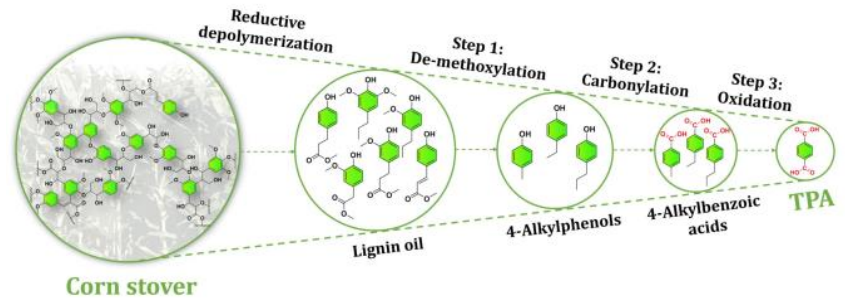

Scheme 1. Chemical funneling and functionalization of lignin derived phenolic stream into terephthalic acid (TPA).

Hydro-treating of lignin-derived phenolic model compounds (e.g. guaiacol and eugenol) over supported metal catalysts have been extensively investigated, but various products including phenols, alkanes and arenes, are all possible. ${ }^{[13]}$ To make the strategy viable, the key for step 1 is to identify a suitable catalyst that can selectively remove the methoxyl group while keeping the phenolic hydroxyl group and benzene ring untouched. We explored the de-methoxylation performance of a series of supported molybdenum oxide catalysts ${ }^{[14]} \quad\left(\mathrm{MoO}_{\mathrm{x}} / \mathrm{TiO}_{2}\right.$, 
$\mathrm{MoO}_{x} / \mathrm{CeO}_{2}, \mathrm{MoO}_{x} / \mathrm{SiO}_{2}, \mathrm{MoO}_{x} / \mathrm{AC}$ and $\left.\mathrm{MoO}_{x} / \mathrm{Al}_{2} \mathrm{O}_{3}\right)$ using 4propylguaiacol as a model compound (Figure 1a). The highest yield of the target product 4-propylphenol (51\%) was obtained over $\mathrm{MoO}_{\times} / \mathrm{AC}$ among all screened catalysts at $593 \mathrm{~K}, 30$ bar $\mathrm{H}_{2}$ after $2 \mathrm{~h}$, possibly due to the inert nature and high surface area of activated carbon support. Time-on-stream performance for the de-methoxylation of 4-propylguaiacol over $\mathrm{MoO}_{x} / \mathrm{AC}$ catalyst is shown in Figure 1b. Under applied reaction conditions, the direct de-methoxylation of 4-propylguaiacol to 4-propylphenol appears to be the dominant pathway. The yields of 4propylphenol reached $71 \%$ with full conversion after 4 h. 2 methyl-4-propylphenol, 1,2-dimethoxy-4-propylbenzene and propylbenzene were detected as the main side products. Methanol originating from the hydrogenolysis of methoxyl group, had reacted with the remaining substrate to become 1,2dimethoxy-4-propylbenzene, which was further transformed into propylbenzene over the $\mathrm{MoO}_{x} / \mathrm{AC}$ catalyst via de-methoxylation. Thus, the yield of 1,2-dimethoxy-4-propylbenzene increased initially but then decreased after $4 \mathrm{~h}$. Additionally, alkylation of 4propylphenol afforded another side product, 2-methyl-4propylphenol. An overall reaction network over $\mathrm{MoO}_{x} / \mathrm{AC}$ catalyst is depicted in Scheme S1.

Next, $\mathrm{MoO}_{x} / \mathrm{AC}$ catalyzed de-methoxylation of corn stoverderived lignin oil was conducted. Corn stover is produced at 216 and 220 million tons every year in the US and China, respectively, ${ }^{[15]}$ and its efficient utilization is a matter that has implications on both environment and economy. Lignin oil was obtained from corn stover by reacting with $\mathrm{H}_{2}$ in methanol over a $\mathrm{Ru} / \mathrm{C}$ catalyst (see $\mathrm{SI}$ for experimental details). A GC spectrum of the product is shown in Figure 1c (black line), where 4ethylphenol, 2-methoxyl-4-propylphenol, methyl 3-(4hydroxyphenyl) propionate, 2,6-dimethoxyl-4-propylphenol, methyl 3-methoxyl-4-hydroxyphenylacetate, methyl 3-(3methoxyl-4-hydroxyphenyl) propionate and methyl coumarate were detected as the main monomers, with a total yield of 34.6 $w t \%$ based on the lignin content (13.5 wt\%) (Table S1). The monomer yields were comparable to the reference (maximum yield: $38 \mathrm{wt} \%) .{ }^{[16]} \mathrm{MoO}_{\times} / \mathrm{AC}$ catalyzed de-methoxylation of the lignin oil obtained from corn stover was then performed. As shown in Figure 1c (red line), the percentage of methoxyl group containing substrates that are the prevailing fraction in lignin oil (black dash rectangle in Figure 1c) dropped drastically to below $10 \%$ after the reaction.

Interestingly, the MoOx/AC catalyst not only catalyzed the cleavage of the methoxyl group but also removed the oxygen in para-substituted ester groups on the phenolic monomers, probably due to the oxygen vacancy on the surface of $\mathrm{MoO}_{x} / \mathrm{AC}$ catalyst that is known to be active in ester deoxygenation. This is a significant advantage, since the carboxyl group containing compounds, which are the dominant fraction in corn stover lignin oil, can be converted into 4-alkylphenols after the reaction. Results for the de-methoxylation of 2,6-dimethyl-4-propylphenol monomer are unsatisfactory, in accordance with the previous reports, ${ }^{[6 c, 17]}$ but it is not a significant issue since it only accounts for 10 wt $\%$ in monomers. Three alkyl phenols, including 4methylphenol, 4-ethylphenol and 4-propylphenol are the dominant fractions after de-methoxylation, which are ideal for further transformation (red dash rectangle in Figure 1c and Table S2). a)
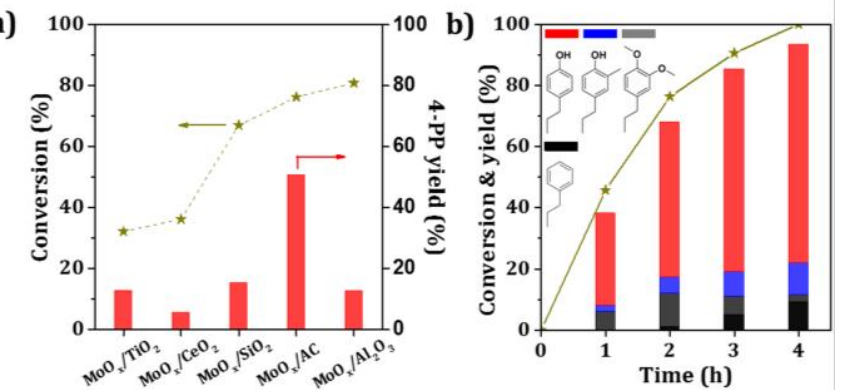

c)

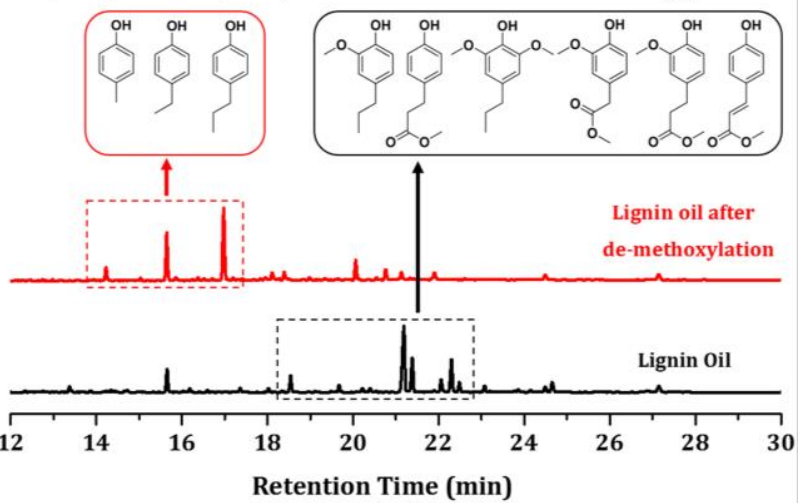

Figure 1. a) De-methoxylation of 4-propylguaiacol over molybdenum oxide catalysts (4-propylphenol was denoted as 4-PP). Reaction conditions: 4 propylguaicol $1 \mathrm{mmol}$, catalyst $0.1 \mathrm{~g}$, octane (internal standard) $0.07 \mathrm{~g}$, toluene $3 \mathrm{~mL}, \mathrm{H}_{2}=30$ bar, $\mathrm{T}=593 \mathrm{~K}, \mathrm{t}=2 \mathrm{~h}$; b) Time-on-stream performance of demethoxylation of 4-propylguaical over $\mathrm{MoO}_{x} / \mathrm{AC}$ catalyst. Reaction conditions: same as in a); c) Black line: A GC spectrum of the obtained lignin oil from corn stover. Reaction conditions: corn stover $1.0 \mathrm{~g}, 5 \% \mathrm{Ru} / \mathrm{C} 0.1 \mathrm{~g}$, methanol 250 $\mathrm{mL}, \mathrm{H}_{2}=30$ bar, $\mathrm{T}=513 \mathrm{~K}, \mathrm{t}=3 \mathrm{~h}$; Red line: $\mathrm{A} \mathrm{GC}$ spectrum of lignin oil after de-methoxylation. Reaction conditions: lignin oil $0.11 \mathrm{~g}, \mathrm{MoO}_{x} / \mathrm{AC} 0.2 \mathrm{~g}$, toluene $3 \mathrm{~mL}, \mathrm{H}_{2}=30$ bar, $\mathrm{T}=593 \mathrm{~K}, \mathrm{t}=10 \mathrm{~h}$

Insertion of $\mathrm{CO}$ into the $\mathrm{C}-\mathrm{OH}$ bond in 4-alkylphenols is the second step. We used Pd-based catalyst to promote the reaction, and 4-propylphenol was chosen as a model substrate. Due to the inert nature of the phenolic hydroxyl group, 4propylphenol was first mixed with triflic anhydride to form 4propylphenol triflate (Figure $\mathrm{S} 1 \& 2$ ), and then the triflate was converted into 4-propylbenzoic acid (Figure S3 \& 4) over Pd catalysts with nine phosphine ligands (as shown in Figure 2). Several diphosphine ligands, like Xantphos (L1), dcpp (L2), dppe (L3) and dppp (L4), as well as SPhos (L5), a typical Buchwald ligand, exhibited no activity. $12 \%$ yield of 4 propylbenzoic acid was obtained with monodentate phosphine ligand, $\mathrm{PPh}_{3}$ (L6), after $12 \mathrm{~h}$ at $60{ }^{\circ} \mathrm{C}$. BINAP-type ligands exhibited much better activity, with yields of $21 \%$ and $42 \%$ yield being obtained for BINAP (L7) and Tol-BINAP (L8) respectively. The best performance (47\%) was observed with ferrocene-type phosphine ligands, dppf (L9). The yield of 4-propylbenzoic acid further increased to $78 \%$ using the $\mathbf{L} 9$ ligand at a reaction time of $24 \mathrm{~h}$. Different solvents including DMSO, DMA, NMP, $\mathrm{CH}_{3} \mathrm{CN}$ and DMF, were tested but no activity was observed except reactions in DMSO, which may have form strong complexes with $\mathrm{Pd}$ (II) during the reaction. 


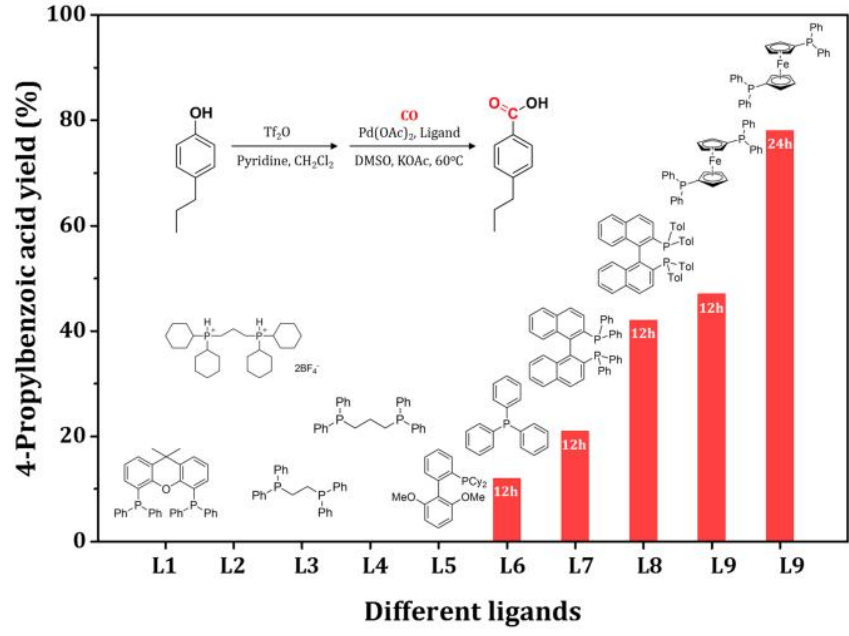

Figure 2. Carbonylation of 4-propylphenol to 4-propylbenzoic acid over different phosphine ligands. Reaction conditions: (1) 4-propylphenol $10 \mathrm{mmol}$, DCM $50 \mathrm{~mL}$, pyridine $20 \mathrm{mmol}$, triflic anhydride $12 \mathrm{mmol}$; (2) 4-propylphenol triflate $2 \mathrm{mmol}, \mathrm{Pd}(\mathrm{OAc})_{2} 5 \mathrm{~mol} \%$, ligand $20 \mathrm{~mol} \%$, KOAc $8 \mathrm{mmol}$, DMSO 25 $\mathrm{mL}, \mathrm{CO}$ balloon, $\mathrm{T}=60^{\circ} \mathrm{C}$.

A mixture of 4-methylphenol, 4-ethylphenol and 4propylphenol, in the same portions as obtained after the demethoxylation of lignin oil, was used as the substrate for the carbonylation reaction. To our delight, close to $75 \%$ average yields of 4-alkylbenzoic acids (4-methyl benzoic acid 72\%, 4ethylbenzoic acid $75 \%$ and 4-propylbenzoic acid 76\%) were obtained, demonstrating that the carbonylation protocol developed in the study is applicable to the transformation of various lignin derived alkyl phenols into the corresponding alkyl benzoic acids in one-pot.

In the last step, 4-alkylbenzoic acids are converted into TPA (step 3). Compared to stoichiometric oxidants (such as $\mathrm{KMnO}_{4}$ or $\mathrm{K}_{2} \mathrm{Cr}_{2} \mathrm{O}_{7}$ ), oxidants like $\mathrm{H}_{2} \mathrm{O}_{2}$ or $\mathrm{O}_{2}$ are preferred due to their economic and environmental benefits. The Co- $\mathrm{Mn}-\mathrm{Br}$ system is one of the most active and selective catalysts for aerobic oxidation reactions, such as in the oxidation of $p$-xylene, ${ }^{[3]}$ and therefore, it was selected to convert 4-propylbenzoic acid. The reaction didn't occur in the presence of $\mathrm{Co}(\mathrm{OAc})_{2}, \mathrm{Mn}(\mathrm{OAc})_{2}$ or $\mathrm{KBr}$ as catalysts (Table S3, entries 1 to 3 ), and no activity was observed with the combined use of $\mathrm{Co}(\mathrm{OAc})_{2}+\mathrm{Mn}(\mathrm{OAc})_{2}$ (Table S3, entry 4). $6 \%$ and $11 \%$ yields of TPA were obtained when $\mathrm{Co}(\mathrm{OAc})_{2}+\mathrm{KBr}$ and $\mathrm{Mn}(\mathrm{OAc})_{2}+\mathrm{KBr}$ were used as catalysts, respectively (Table $\mathrm{S} 3$, entries 5 and 6 ). When all three components were added, the yield of TPA reached $60 \%$ under the same reaction conditions (Table S3, entry 7). Replacing $\mathrm{KBr}$ by $\mathrm{KCl}$ or $\mathrm{KI}$ completely quenched catalytic activity, suggesting the crucial role of $\mathrm{Br}^{-}$(Table S3 entries 8 and 9). The reaction activity of various cobalt precursors follow the order: $\mathrm{Co}(\mathrm{OAc})_{2}>\mathrm{Co}(\mathrm{acac})_{2}>\mathrm{CoCl}_{2}>\mathrm{Co}\left(\mathrm{NO}_{3}\right)_{2}$ (Table S3, entries 1, 8, 9 and 10). Similarly, $\mathrm{Mn}(\mathrm{OAc})_{2}$ exhibited higher activity compared to $\mathrm{MnSO}_{4}$ and $\mathrm{MnCl}_{2}$ (Table S3, entries 11 and 12). We also performed the reaction using $\mathrm{Ni}(\mathrm{OAc})_{2}, \mathrm{Zn}(\mathrm{OAc})_{2}$ or $\mathrm{Cu}(\mathrm{OAc})_{2}$ in the presence of $\mathrm{Mn}(\mathrm{OAc})_{2}$ and $\mathrm{KBr}$ (Table S3, entries 15-17), but the yield of TPA was much lower $(<10 \%)$. a)

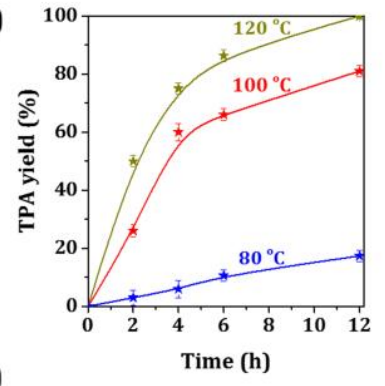

b)
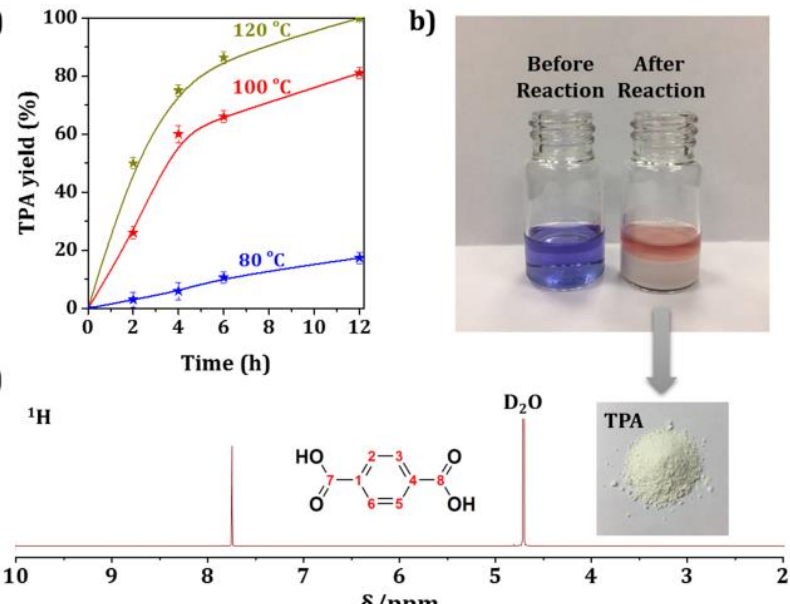

${ }^{13} \mathrm{C}$

$\delta / p p m$

$2,3,5,6)$

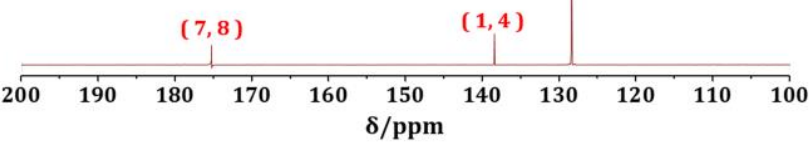

Figure 3. a) Time-on-stream performance for oxidation of 4-propylbenzoic acid over Co-Mn-Br catalyst at different reaction temperature. Reaction conditions: 4-propylbenzoic acid $2 \mathrm{mmol}, \mathrm{Co}(\mathrm{OAc})_{2} 2.5 \mathrm{~mol} \%, \mathrm{Mn}(\mathrm{OAc})_{2} 2.5$ $\mathrm{mol} \%, \mathrm{KBr} 5.0 \mathrm{~mol} \%$, acetic acid $3 \mathrm{~mL}, \mathrm{O}_{2}=10$ bar; b) Pictures before reaction versus after reaction for oxidation of mimetic mixture over $\mathrm{Co}-\mathrm{Mn}-\mathrm{Br}$ catalyst. Reaction conditions: 4-methylbenzoic acid $0.1 \mathrm{mmol}$, 4-ethylbenzoic acid $0.7 \mathrm{mmol}$, 4-propylbenzoic acid $1.2 \mathrm{mmol}, \mathrm{Co}(\mathrm{OAc})_{2} 2.5 \mathrm{~mol} \%, \mathrm{Mn}(\mathrm{OAc})_{2}$ $2.5 \mathrm{~mol} \%, \mathrm{KBr} 5.0 \mathrm{~mol} \%$, acetic acid $3 \mathrm{~mL}, \mathrm{O}_{2}=10 \mathrm{bar}, \mathrm{T}=120^{\circ} \mathrm{C}, \mathrm{t}=12 \mathrm{~h}$; c) ${ }^{1} \mathrm{H}$ and ${ }^{13} \mathrm{C}$ NMR spectra for the obtained product from Figure $3 \mathrm{~b}$.

From above, the co-existence of $\mathrm{Co}(\mathrm{OAc})_{2}, \mathrm{Mn}(\mathrm{OAc})_{2}$ and $\mathrm{KBr}$ were essential for the high activity. Time-on-stream curves at different reaction temperatures (Figure $3 a$ ) suggest that the reaction proceeded smoothly at $80{ }^{\circ} \mathrm{C}$ with $17 \%$ yield of TPA after $12 \mathrm{~h}$. The yield increased significantly to $81 \%$ after raising the temperature to $100^{\circ} \mathrm{C}$. Further increasing the temperature to $120{ }^{\circ} \mathrm{C}$ enabled quantitative formation of TPA. Encouraged by the effectiveness of the system on the model compound, a mixture of 4-methylbenzoic acid, 4-ethylbenzoic acid and 4propylbenzoic acid, obtained after the carbonylation step, was converted over $\mathrm{Co}(\mathrm{OAc})_{2}+\mathrm{Mn}(\mathrm{OAc})_{2}+\mathrm{KBr}$ catalyst with 10 bar $\mathrm{O}_{2}$ at $120^{\circ} \mathrm{C}$. All the three substrates were converted into TPA in close to $100 \%$ yield within a single reaction vessel.

Before starting the reaction, the reaction media containing substrates, catalyst $\left(\mathrm{Co}(\mathrm{OAc})_{2}+\mathrm{Mn}(\mathrm{OAc})_{2}+\mathrm{KBr}\right)$ and acetic acid was a transparent homogeneous solution with a deep blue color (Figure $3 b$ ). After the reaction, the color of the solution changed to light red. Notably, large amounts of TPA in the form of white powder appeared at the bottom of the reactor, facilitating its purification from the reaction mixture. TPA was obtained simply by filtering and then washing with water. The NMR spectrum of the as-obtained white powder, dissolved in $\mathrm{NaOH} / \mathrm{D}_{2} \mathrm{O}$, is shown in Figure 3c. Single ${ }^{1} \mathrm{H}$ signal $\left(\delta_{1 \mathrm{H}}=7.83\right.$ ppm) and three characteristic ${ }^{13} \mathrm{C}$ signal $\left(\delta_{13 \mathrm{C}}=175.30,138.51\right.$, and $128.49 \mathrm{ppm}$ ) belonging to TPA were detected, while no other peak is observable indicating the high purity of the product. 
Purification of products from the reaction media is often a major challenge in biorefineary. Precipitation of the desired product from the solution with close to $100 \%$ purity is uncommon in biomass valorization, and this feature will significantly facilitate post-treatment and reduce the process cost.

The three chemical reactions developed above bridge corn stover lignin with TPA. On a lignin basis, $16.1 \mathrm{wt} \%$ of 4 alkylphenols were obtained after the de-methoxylation step, which can be converted into $14.8 \mathrm{wt} \%$ of 4 -alkylbenzoic acids via carbonylation, and finally to $15.5 \mathrm{wt} \%$ TPA after oxidation (Figure S5. Of note, the yields of the 4-alkylbenzoic acids in our study were obtained from a mimetic mixtures of 4-alkylphenols). Based on this, we propose a conceptual design for the full utilization of corn stover for polyethylene terephthalate and other value-added applications (Figure S6). Lignin is converted into lignin oil via reductive depolymerization and then transformed into TPA based on the strategy developed in the current work. Acid catalysis of polysaccharide offers a series of high-value biomass platform molecules, such as glucose, xylose, 5hydromethylfurfural, furfural, levulinic acid, etc. Hydrogenolysis of sugars affords ethylene glycol (EG) and propylene glycol, which copolymerize with TPA to access $100 \%$ bio-based polyethylene terephthalate (PET) and other plastics.

To summarize, we developed a new chemical route that could be used to produce TPA from corn stover-derived lignin oil via de-methoxylation, carbonylation and oxidation steps. A salient feature is that TPA precipitates from the solution in the final step in an almost pure form, avoiding any complex purification process. This work provides an example of chemical funneling and functionalization of complex lignin-derived monomers into a single, value-added compound.

\section{Acknowledgements}

The authors thank the Tier-1 \& Tier-2 projects from Singapore Ministry of Education for financial supports (R-279-000-462-112, and R-279-000-479-112). We thank Mr. Erwin Tan for proof reading the manuscript.

Keywords: carbonylation $\cdot$ de-methoxylation $\cdot$ lignin $\cdot$ renewable chemical $\bullet$ terephthalic acid

[1] a) A. Corma, S. Iborra, A. Velty, Chem. Rev. 2007, 107, 2411-2502; b) C. Li, X. Zhao, A. Wang, G. W. Huber, T. Zhang, Chem. Rev. 2015, 115, 11559-11624; c) T. Renders, S. Van den Bosch, S.-F. Koelewijn, W. Schutyser, B. F. Sels, Energ. Environ. Sci. 2017, 10, 1551-1557; d) W. Schutyser, T. Renders, S. Van den Bosch, S.-F. Koelewijn, G. T. Beckham, B. F. Sels, Chem. Soc. Rev. 2018, 47, 852-908; e) Z. Sun, B. I. Fridrich, A. de Santi, S. Elangovan, K. Barta, Chem. Rev. 2018, 118, 614-678.

[2] a) J. Pang, M. Zheng, R. Sun, A. Wang, X. Wang, T. Zhang, Green Chem. 2016, 18, 342-359; b) Grand View Research, www.grandviewresearch.com/press-release/global-purified-terephthalicacid-pta-market.

[3] R. A. Tomás, J. C. Bordado, J. F. Gomes, Chem. Rev. 2013, 113, 7421-7469.

[4] A. E. Settle, L. Berstis, N. A. Rorrer, Y. Roman-Leshkóv, G. T. Beckham, R. M. Richards, D. R. Vardon, Green Chem. 2017, 19, 34683492.

[5] P. C. Bruijnincx, B. M. Weckhuysen, Angew. Chem. Int. Ed. 2013, 52, 11980-11987; Angew. Chem. 2013, 125, 12198-12206.

[6] a) M. Wang, M. Liu, H. Li, Z. Zhao, X. Zhang, F. Wang, ACS Catal. 2018, 8, 6837-6843; b) J. Zhang, L. Lombardo, G. Gözaydın, P. J. Dyson, N. Yan, Chinese J. Catal. 2018, 39, 1445-1452; c) X. Huang, J. Ludenhoff, M. Dirks, X. Ouyang, M. D. Boot, E. J. Hensen, ACS Catal. 2018, 8, 11184-11190.

[7] Z. Bai, W. C. Phuan, J. Ding, T. H. Heng, J. Luo, Y. Zhu, ACS Catal. 2016, 6, 6141-6145.

[8] R. Behling, S. Valange, G. Chatel, Green Chem. 2016, 18, 1839-1854.

[9] N. Yan, C. Zhao, P. J. Dyson, C. Wang, L. t. Liu, Y. Kou, ChemSusChem 2008, 1, 626-629.

[10] L. Shuai, M. T. Amiri, Y. M. Questell-Santiago, F. Héroguel, Y. Li, H. Kim, R. Meilan, C. Chapple, J. Ralph, J. S. Luterbacher, Science 2016, 354, 329-333.

[11] a) E. M. Anderson, M. L. Stone, R. Katahira, M. Reed, G. T. Beckham, Y. Román-Leshkov, Joule 2017, 1, 613-622; b) I. Kumaniaev, E. Subbotina, J. Sävmarker, M. Larhed, M. V. Galkin, J. S. Samec, Green Chem. 2017, 19, 5767-5771.

[12] J. G. Linger, D. R. Vardon, M. T. Guarnieri, E. M. Karp, G. B. Hunsinger M. A. Franden, C. W. Johnson, G. Chupka, T. J. Strathmann, P. T. Pienkos, G. T. Beckham, Proc. Natl. Acad. Sci. USA 2014, 111, 1201312018.

[13] a) G. H. Wang, Z. Cao, D. Gu, N. Pfänder, A. C. Swertz, B. Spliethoff, H. J. Bongard, C. Weidenthaler, W. Schmidt, R. Rinaldi, F. Schüth, Angew. Chem. Int. Ed. 2016, 55, 8850-8855; Angew. Chem. 2016, 128, 89969001; b) Z. Cao, J. Engelhardt, M. Dierks, M. T. Clough, G. H. Wang, E. Heracleous, A. Lappas, R. Rinaldi, F. Schüth, Angew. Chem. Int. Ed. 2017, 56, 2334-2339; Angew. Chem. 2017, 129, 2374-2379.

[14] T. Prasomsri, T. Nimmanwudipong, Y. Román-Leshkov, Energ. Environ. Sci. 2013, 6, 1732-1738.

[15] J.-J. Dong, J.-C. Ding, Y. Zhang, L. Ma, G.-C. Xu, R.-Z. Han, Y. Ni, FEMS Microbiol. Lett. 2016, 363, 1-6.

[16] E. M. Anderson, R. Katahira, M. Reed, M. G. Resch, E. M. Karp, G. T. Beckham, Y. Román-Leshkov, ACS Sustain. Chem. Eng. 2016, 4, 6940-6950.

[17] D. Verboekend, Y. Liao, W. Schutyser, B. F. Sels, Green Chem. 2016, 18, 297-306. 
Entry for the Table of Contents (Please choose one layout)

Layout 1:

\section{COMMUNICATION}

Renewable PET: Terephthalic acid (TPA) with high yield and purity from corn stover lignin is achieved through a three-step conversion strategy.
S. Song, J. G. Zhang, G. Gözaydın, N. Yan*

Page No. - Page No.

Production of Terephthalic Acid from Corn Stover Lignin 